\section{Avulsion of Previously Implanted Stent by Directional Coronary Atherectomy \\ - Intravascular Ultrasound and Angioscopic Evaluation -}

Yasuyuki Egami, MD; Ryu Shutta, MD;

Kohei Ukita, MD; Akito Kawamura, MD;

Hitoshi Nakamura, MD; Yutaka Matsuhiro, MD;

Koji Yasumoto, MD; Masaki Tsuda, MD;

Naotaka Okamoto, MD; Akihiro Tanaka, MD;

Yasuharu Matsunaga-Lee, MD;

Masamichi Yano, MD, PhD;

Masami Nishino, MD, PhD; Jun Tanouchi, MD, PhD

W

e present a case of a 64-year-old man with severe in-stent restenosis of a bare metal stent $(4.0 \times 15 \mathrm{~mm})$ in the left anterior descending (LAD) (Figure A). Because the coronary angiogram suggested massive neointimal hyperplasia in the stent, we chose to use a debulking device to reduce the in-stent tissue and gain sufficient lumen area. Intravascular ultrasound (IVUS) showed diffuse intimal hyperplasia and no stent malapposition (Figure A-a-d). Directional coronary atherectomy (DCA) was performed at $20 \mathrm{psi}$ to the distal section of the stent, followed by the proximal section. There was an abnormal sound after the last attempt at DCA and the device was entrapped within the stent. Careful retrieval revealed a metal mass wrapped around the housing of the device (Figure B). Subsequent coronary angiography showed a filling defect in the mid-LAD (Figure C). To evaluate the vessel's condition, both IVUS and coronary angioscopy were performed and revealed no stent structure; angioscopy showed mobile, peeled intima but no thrombi (Figure D,E; Supplementary Movies 1,2). We implanted a new bare metal stent.

It is very rare that a stent will be avulsed by a coronary intervention. ${ }^{1}$ Attention should be paid to stent avulsion when performing DCA for in-stent restenosis.

\section{Funding / Disclosures}

None.

\section{Reference}

1. Matsuhiro Y, Shutta R, Egami Y, Nishino M, Tanouchi J. Orbital atherectomy through left main stent struts complicated by catheter entrapment and stent avulsion. JACC Case Rep 2020; 2: $709-710$.

\section{Supplementary Files}

Supplementary Movie 1. IVUS image after DCA.

Supplementary Movie 2. Coronary angioscopic image after DCA.

Please find supplementary file(s);

http://dx.doi.org/10.1253/circj.CJ-20-0610

Received June 10, 2020; revised manuscript received July 13, 2020; accepted July 28, 2020; J-STAGE Advance Publication released online October 15, 2020 Time for primary review: 26 days

Division of Cardiology, Osaka Rosai Hospital, Sakai, Japan

Mailing address: Masami Nishino, MD, PhD, FACC, FESC, Division of Cardiology, Osaka Rosai Hospital, 1179-3 Nagasone-cho, Sakai, Osaka 591-8025, Japan. E-mail: mnishino@osakah.johas.go.jp

All rights are reserved to the Japanese Circulation Society.

For permissions, please e-mail: cj@j-circ.or.jp

ISSN-1346-9843

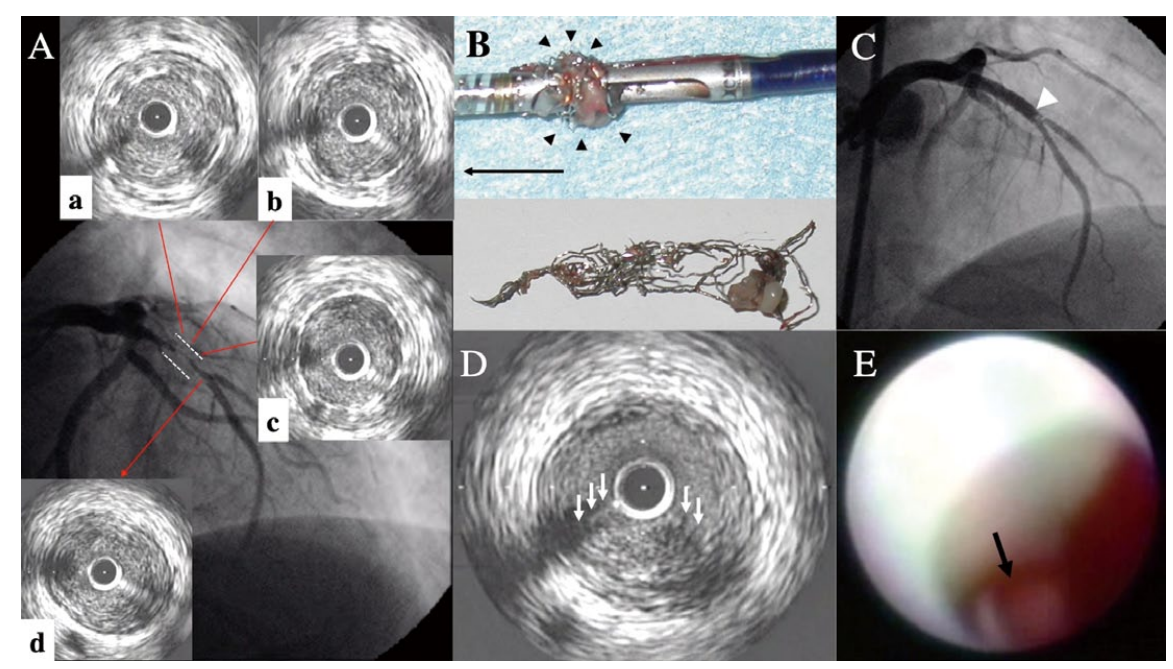

Figure. (A) Coronary angiography and intravascular ultrasound before DCA. The dashed lines indicate the contour of the previously implanted stent. (a) Proximal site, (b) middle site and (c) distal site of in-stent restenosis. (d) Distal edge of stent. (B) (Upper) Retrieved DCA catheter and metallic mass with white tissue (black arrowheads). Black arrow indicates the direction of the tip of the DCA catheter. (Lower) Retrieved stent with white tissue. (C) Coronary angiogram showing filling defect in the LAD (white arrowhead). (D) Intravascular ultrasound showed the protruding plaque (white arrows). (E) Angioscopy showing peeled intima (black arrow). DCA, directional coronary atherectomy; LAD, left anterior descending coronary artery. 